\title{
Psychometric properties of Liverpool Stoicism Scale (LSS) in a cohort of patients with resected cancer in adjuvant treatment
}

Caterina Calderón ${ }^{1}$, Pere J. Ferrando ${ }^{2}$, Urbano Lorenzo-Seva ${ }^{2}$, Alberto Carmona-Bayonas ${ }^{3}$, MD, Carlos Jara ${ }^{4}$, Francisco Ayala de la Peña ${ }^{3}$, Carmen Beato ${ }^{5}$, Avinash Ramchandani ${ }^{6}$, Teresa García ${ }^{3}$, Montserrat Mangas-Izquierdo ${ }^{7}$, Beatriz Castelo ${ }^{8}$,

Olga Donnay ${ }^{9}$, María del Mar Muñoz ${ }^{10}$, Eva Martínez de Castro ${ }^{11}$, Sara García ${ }^{12}$, Ismael Ghanem ${ }^{8}$, Teo Mellen ${ }^{13}$ and Paula Jiménez-Fonseca ${ }^{14}$

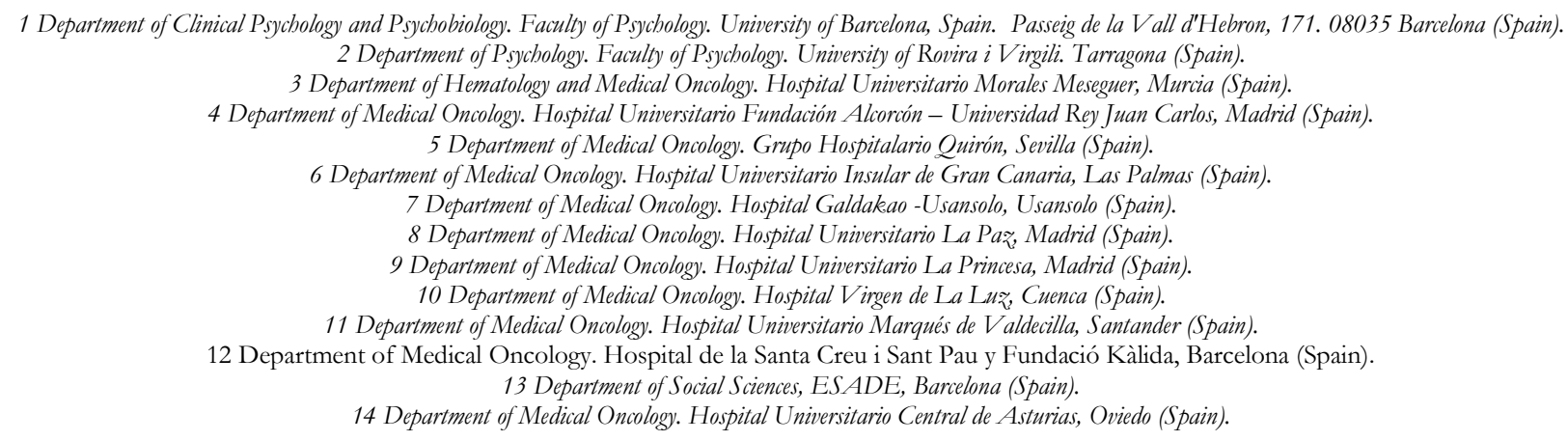

Título: Propiedades psicométricas de la Liverpool Stoicism Scale (LSS) en una cohorte de pacientes con cáncer resecado en tratamiento adyuvante. Resumen: El estoicismo se ha utilizado para describir una amplia gama de comportamientos frente a la enfermedad que van desde el silencio a la resistencia a la adversidad. Este estudio tiene dos objetivos: 1) analizar las propiedades psicométricas de la versión española del LSS; 2) evaluar la relación entre estoicismo, género, edad y el modelo de los cinco grandes factores de personalidad. NEOcoping es un estudio prospectivo, multicéntrico, observacional, no-intervencionista. Los pacientes fueron reclutados consecutivamente en 13 hospitales universitarios de España. Se aplicó la Liverpool Stoicism Scale (LSS) y el Big Five Inventory (BFI-10). Participaron 443 pacientes (250 mujeres) con una edad media de 59,8 años $(S D=12,3)$. El cáncer de colon y mama fueron los más frecuentes. A nivel de escala total, la puntuación media de la LSS fue inferior a la muestra Británica. La estructura propuesta en cuatro factores proporciona un buen ajuste a los datos, y las puntuaciones en las escalas derivadas presentan fiabilidades aceptables. El rasgo de personalidad de introversión fue capaz de predecir el $4,1 \%$ de la variancia de estoicismo $(p<, 001)$. Aunque debe ser mejorada, la LSS presenta globalmente unas propiedades psicométricas aceptables para evaluar el estoicismo en pacientes españoles con cáncer resecado.

Palabras clave: Actitud; estoicismo; cáncer; estudio psicométrico; personalidad; afrontamiento.

\section{Introduction}

Stoicism, the philosophy of the stoics, followers of Zeno of Citium (334 B.C. - 260 B.C.) advocated, among other premises, keeping calm in situations of difficulty, and acceptance of adversity without complaint (Addis \& Mahalik, 2003; Erskine, 2000). In its classical interpretation, the concept asserted that personal indifference in light of the pain-pleasure binomial, as well as strict control of the emotional, as the best way to achieve happiness. More recently, Wagstaff and Rovledge (1995) depicted the concept of stoicism as a trait

* Correspondence address [Dirección para correspondencia]: Caterina Calderon. Department of Clinical Psychology and Psychobiology. Faculty of Psychology. University of Barcelona. Passeig de la Vall d'Hebron, 171.08035 Barcelona (Spain).E-mail: ccalderon@ub.edu

\begin{abstract}
Stoicism has been used to describe a wide range of behaviors in the face of disease that go from silence, resistance to the adversity, or 'to make the best of a bad disease'. This study pursued two objectives: 1) analyze the psychometric properties of the Spanish version of the LSS; 2) assess the relation between stoicism and gender, age, and the five-factor personality model. NEOcoping is a prospective, multicenter, observational, non-interventionist study. Patients were recruited consecutively at thirteen Spanish teaching hospitals. The following scales were administered: Liverpool Stoicism Scale (LSS) and Big Five Inventory (BFI-10). A total of 443 patients (250 females) with a mean age of 59.8 years $(S D=12.3)$ were enrolled. Colon cancer was the most common, followed by breast cancer. At the total-scale level, mean LSS was lower than the originally reported British sample. The four-factor structure fitted the data well, had a clear interpretation, and the derived scales showed acceptable reliabilities. The personality trait of introversion predicted $4.1 \%$ of the variance of stoicism $(p<.001)$. Even though it needs to be improved, the LSS scale demonstrates acceptable psychometric properties to appraise stoicism in the Spanish population with resected cancer.

Key words: Attitude; stoicism; cancer; psychometric study.
\end{abstract}

or disposition characterized by the lack of emotional expression and increased capacity to withstand life's vicissitudes.

Despite the possible explanatory nature this might have in the field of the health, and especially in oncological patients, stoicism has been fairly ignored in these spheres (Becker, 2003; Spiers, 2006). Within its phenomenology, stoicism has been used to describe a wide range of behaviors in the face of disease that go from silence, resistance to the adversity, bearing pain without complaining, or 'to make the best of a bad job' (Spiers, 2006). Some studies have shown that the adaptive or maladaptive effects of stoicism as a personality trait would be highly sensitive to the context of health, and that might have treatment and prognostic implications (Furnham, Petrides, Sisterson, \& Baluch, 2003; Murray et al., 2008; Spiers, 2006; Witte, Gordon, Smith, \& Van Orden, 2012). Thus, for Spiers (2006) a stoical attitude 
in the face of pain would be particularly adaptive and efficacious in the degree to which the person conserved their ability to know their own limits and will adopt proactive measures to keep the symptomatology, p.e. pain, within these acceptable limits. In contrast, the stoical attitude would restrict attempts at appropriate medical intervention and it would therefore be maladaptive if the inconsistency between the stoical individual's verbal and non-verbal behavior hindered the appreciation of patient's actual clinical situation (p.e. an individual who suffers intense pain, but doesn't show it). Several investigations have suggested that measuring this construct could be useful in certain clinical contexts (Buckley \& Ó Tuama, 2010; George \& Fleming, 2004; Moore, Grime, Campbell, \& Richardson, 2013; Murray et al., 2008; O’Brien, Hunt, \& Hart, 2005; Yong, 2006). Hence, better characterization of stoical patients would enable more efficacious strategies to be designed for interventions such as decision-making in oncology.

At present, the only psychometrically validated tool to measure stoical traits is the Liverpool Stoicism Scale (LSS). According to Wagstaff and Rovledge (1995), the LSS hinges on a definition of stoicism based on the absence of emotional involvement (for instance, «I do not get emotionally involved when I see suffering on television»), the nonexpression of emotion (for instance, «I tend not to express my emotions»), and the ability to withstand difficulties (for instance, "One should keep a 'stiff upper lip'») (Furnham et al., 2003; Murray et al., 2008; Wagstaff \& Rowledge, 1995). In the process of designing the LSS, the authors did not conduct a factor analysis, and the scale was directly considered as unidimensional, measuring a single general construct. Subsequent factorial studies aimed at assessing the dimensionality and structure of the LSS have not arrived at consistent results. Authors such as Furnham et al. (2003) have highlighted the presence of four factors that would account for $47 \%$ of the variance, Gaitniece-Putañe (2005) have posited a three-factor model that would explain $37.9 \%$ of scale or, a single-factor model, albeit eliminating the items with a lower factor loading, whereas Murray et al. (2008) propose the scale's unidimensional structure that would account for $25.9 \%$ of the variance.

Currently, the LSS has not been translated or validated in Spanish, limiting its use in Spanish-speaking patients from a specific cultural and social context. A sample of patients who had undergone surgery for cancer in its early stage, after the first consultation with the oncologist to decide on adjuvant treatment has been used as a model for the scale's adaptation into Spanish. Despite the fact that this cohort has a relatively good short-term prognosis following neoplasm resection, it is an interesting population to appraise the effect of resignation in non-terminal patients. These individuals must confront the perspective of a treatment, adjuvant chemotherapy that is loaded with uncertainty as to prognosis, efficacy, and tolerance. Thus, stoical traits could affect specific decisionmaking, be barriers to communication, and cause clinical uncertainty with impoverished quality of life, tolerance to treatments, and the emergence of adverse effects, such as anxiety and depression and could influence prognosis (Spiers, 2006).

The use of the LSS-based measures of stoicism suggests that men have higher levels of stoicism (Wagstaff \& Rowledge, 1995), which is consistent with the traditional notion that stoicism is associated with being male (Fergus, Gray, Fitch, Labrecque, \& Phillips, 2002; Seale, 2002) and older adult (Moore et al., 2013; Yong, 2006). Some authors have suggested that men and older adults are more stoical because it is harder for them to identify and express their emotions (Gaitniece-Putāne, 2006). However, Pinnock, O'Brien, and Marshall (1998) point out that stoicism could be a potentially maladaptive behavior linked to negative attitudes toward pursuing psychological help. When men perceive disease as 'weakness', they tend to adopt a more stoical attitude and seek less help (Addis \& Mahalik, 2003; Pinnock et al., 1998). Sobralske (2006) attributed this to the fear and shame of appearing less manly. Also, stoicism can be considered a trait or disposition of personality, Murray et al. (2008) found that stoicism is inversely related to the openness to experience and they considered that openness was a predictor of emotional sensitivity to the change (Murray, Allen, Rawlings, \& Trinder, 2002). It is in this regard that stoicism may be more related with personality trait of introversion. Introverted people tend to have qualities such as quiet and reserved (Park et al., 2013).

The general purpose of this study is to assess the psychometric properties of the Spanish version of the LSS in the population above described. The first part of the assessment is internal, and focuses on the dimensionality and structure of the scale, as well as the reliability of the derived scores. The second part is a validity study aimed at assessing the relationship between stoicism and gender, age, and the dimensions of the five factor personality model.

\section{Method}

\section{Participants}

Suitable patients for inclusion were adults ( $\geq 18$ years) who had a histologically confirmed, non-advanced solid tumor treated with surgery for which international clinical guidelines consider that adjuvant treatment may be an option. The patient should be expected to be followed in the center where the first visit takes place during all adjuvant treatment. The evaluation was performed in all cases approximately 2-4 weeks following of the operation, within the context of the patients' first visit to Medical Oncology Department to decide on adjuvant chemotherapy with or without radiotherapy, once any possible complications from the surgery had passed.

Patients were excluded if they had a metastatic disease, if they were treated with preoperative radiotherapy or chemotherapy or only with adjuvant hormonal therapy or radiotherapy without chemotherapy. Patients having physical 
conditions, comorbidity and/or age that preclude chemotherapy and those with personal, psychological, family, sociological, geographical, and/or underlying medical condition that, in the investigator's opinion, might hinder the individual's ability to participate in the study were also excluded, given that these patients did not have to confront the resignation of the decision-making process regarding adjuvant therapy.

Of the 488 patients screened, 45 were not eligible (14 did not meet inclusion criteria; 26 met exclusion criteria and 15 had incomplete data). The final analyzable sample comprises 443 subjects (183 men and 250 women) with a mean age of 59.8 years $(S D=12.3)$. Colon cancer was the most usual $(40.0 \%, n=177)$, followed by breast $(32.7 \%, n=145)$ and stomach cancer $(6.8 \%, n=30)$. Half of the participants had stage I-II disease and the other half had stage III cancer. Regarding the variables associated with the sex, $61 \%$ of men had colon cancer, of which $63 \%$ were stage III, while $56 \%$ of women had breast cancer, $41 \%$ in stage II. All the subjects were deemed to be candidates for adjuvant treatment, with concomitant radiotherapy in $35.2 \%$ of the cases. The mean time between the operation and oncologist consultation was 2.8 weeks $(S D=1.5)$ and $85 \%$ were evaluated in less than one month from the operation. Baseline characteristics are presented in Table 1.

Table 1. Participants' characteristics $(n=443)$.

\begin{tabular}{lcc}
\hline Characteristics & $\mathrm{n}$ & $\%$ \\
\hline Women & 250 & 56.4 \\
Age (years, Mean; SD) & $59.8(12.3)$ & \\
ECOG & & \\
$\quad 0-1$ & 428 & 97.1 \\
Primary tumor & & \\
$\quad$ Colon & 177 & 40 \\
$\quad$ Breast & 145 & 32.7 \\
$\quad$ Stomach & 30 & 6.8 \\
$\quad$ Others & 91 & 20.5 \\
Stage & & \\
$\quad$ I-II & 233 & 52.5 \\
$\quad$ III & 210 & 47.5 \\
Adjuvant radiotherapy & 156 & 35.2 \\
Family history of cancer & 202 & 45.6 \\
\hline Demographic factors & & \\
\hline Residency: town & 188 & 42.4 \\
Patients live with a partner & 346 & 79.9 \\
Children in the family & & \\
$\quad$ No children & 75 & 17.2 \\
$\quad$ One or two children & 266 & 61.4 \\
$\quad$ Three or more children & 102 & 23.5 \\
Primary studies & 252 & 56.9 \\
Not working & 256 & 64.6 \\
\hline Abbriations number SD: & & \\
\hline
\end{tabular}

Abbreviations: $n$ : number SD: Standard Deviation.

\section{Study design and setting}

NEOcoping is a prospective, multicenter, observational study without intervention and patients were recruited consecutively from June 2015 to September 2016 in 13 Spanish teaching hospitals. The study is supported by Continuous
Care Working Group of the Spanish Society of Medical Oncology (SEOM, for its acronym in Spanish).

The protocol was approved by the Ethics Committee at each hospital in accordance with the 1964 Declaration of Helsinki, revised in Seoul in 2008. Data collection was similar for all hospitals. Following a full explanation of the study objectives and procedures, candidates were invited to participate and complete the questionnaires. All participants signed informed consent before the study began. Study participation was voluntary and anonymous.

The physician collected the variables related to the cancer and its treatment. Sociodemographic and psychological data were obtained directly from the patient. The questionnaires were taken up individually during a one-hour session. This visit was structured according to the standard practice at each center, although it was generally agreed that at the very least, the risk of relapse, options for adjuvant treatment, risk of adverse effects, and possible efficacy of the therapy should be discussed with the patient.

Participants were informed that no answers were better or worse to the questions and that all answers should be chosen on the basis of their own experiences. Special attention was paid to ensure data privacy and confidentiality and to avoid random answers. The information was gathered and updated by physicians experienced in cancer, who were trained to comply with the study requirements, through a web-based platform (www.neocoping.es).Telephone data monitoring was performed at all centers. Patients completed the scale at baseline and were followed-up throughout adjuvant treatment.

\section{LSS adaptation process}

The aim of the process of adaptation was to keep the wording of the Spanish version as similar as possible to the original version (LSS) to minimize any differences in item interpretation between both versions. We used the guidelines described for Hambleton, Merenda, and Spielberger (2005) for the process of cross-cultural adaptation of self-reported measures. Specifically, for the translation, two independent bilingual translators, competent in both English and Spanish, translated the original questionnaire from English into Spanish. Translators reached consensus on the translation of words, phrases and items based on the synthesis of the translations, working from the original questionnaire as well as the first translator's and the second translator's versions. For cultural appropriateness and content validity, four independent physicians and psychologist performed testing. They rated understandability, translation equivalences and content validity. Another two bilingual translators who were blind to the original English version back translated the revised Spanish version, and finally, the study directors compared and synthesized the back-translation with original questionnaire, culminating in a final version (see appendix A). The final version was pre-test with the first thirty-four adult patients attended who were invited to participate in this study. Their 
responses were analyzed to identify necessary modifications; however, it was not necessary to make any modification after this pre-test.

\section{Assessments}

Liverpool Stoicism Scale (LSS, Wagstaff \& Rowledge, 1995). The LSS is a self-reported questionnaire designed to measure stoicism; it consists of 20 items whose content refers to lack of emotional involvement, dislike for openly expressing emotion, and the ability to withstand emotion. Responses were recorded on a 5 -point Likert scale ranging from strongly disagree to strongly agree. To prevent response bias, half of the questions were posed in such a way that agreement was synonymous with high stoicism, whereas for the other half, disagreement indicated a high level of stoicism. The answers to these questions were evaluated in reverse. Ten items $(1,2,5$, $7,9,12,13,15,17$, and 18) are reverse-scored. The minimum sum score is 20 and the maximum is 100 . Higher scores indicate greater stoicism levels. The original version is reported to have acceptable internal consistency (Cronbach's alpha $=.83$; Wagstaff \& Rowledge, 1995).

Big Five Inventory (BFI-10, Rammstedt \& John, 2007). The BFI-10 is an abbreviated version of the well-established Big Five Inventory; for the Spanish version see Benet-Martinez and John (1998). The BFI identifies five traits (Introversion $[1]$, Neuroticism [N], Openness to experience [O], Agreeableness [A], and Conscientiousness [C]). BFI traits are measured on 10 items and rated on a five-point scale from 1 'disagree strongly' to 5 'agree strongly'. The minimum sum score is 10 and the maximum is 50 . It has been reported to have good psychometric properties (coefficient alpha reliabilities ranged from .75 to .90 and average.83; Rammstedt, Goldberg, \& Borg, 2010).

The remaining variables consisted of demographic data (e.g. age, marital status, education level, number of children, primary studies, working now, family history of cancer) and medical information (type and stage of cancer, Eastern Cooperative Oncology Group Performance Status (ECOG-PS), and the characteristics of adjuvant treatment chemotherapy with or without radiotherapy).

\section{Statistical Analyses}

Previous descriptive statistics showed that the item distributions were generally asymmetrical and some of them had skewness coefficients larger than one. Furthermore, given that the test is not too long and the sample is reasonably large, we considered that the best choice was to use the underlying-variables approach, and fit the Factor Analysis (FA) model to the inter-item polychoric correlation matrix (see Ferrando \& Lorenzo-Seva, 2014). In this approach what we are fitting is Samejima's (1969) normal-ogive graded response model using an FA parameterization.

In accordance with previous studies, models going from 1 to 4 factors were fitted to the data. The initial solutions were obtained by using Robust Unweighted Least Squares (RULS) estimation with mean-corrected fit statistics as implemented in the FACTOR program (Lorenzo-Seva \& Ferrando, 2006). Assessment of model-data fit was based on the Root mean squared error of approximation (RMSEA) as a measure of approximate fit; the Goodness-of-fit index (GFI) and the Root Mean Square of Residuals (RMSR), as absolute measures of fit; and the non-normed fit index (NNFI) as a relative measure of fit with respect to the null independence model (see e.g. Lloret-Segura, Ferreres-Traver, HernándezBaeza, \& Tomás-Marco, 2014). As additional indices for determining dimensionality we used Optimal implementation of parallel analysis (Timmerman \& Lorenzo-Seva, 2011) and Schwarz's Bayesian Information Criterion (BIC). Initial canonical solutions were next rotated to achieve maximum factor simplicity using the Promin criterion (Lorenzo-Seva, 1999).

Once the item set had been calibrated, fully Informative prior Oblique expected-a-posteriory (EAP) scores (ORION) together with their corresponding marginal reliability estimates were obtained (Ferrando \& Lorenzo-Seva, 2016).

We turn now to the validity assessment. In the correlational-analyses part, we first fitted a multiple linear regression analysis to assess the extent to which personality scores in the 5 scales were able to predict LSS-based stoicism scores. Next, for those predictors found statistically significant, the bivariate correlations between the LSS scores and the corresponding personality scores were obtained. These bivariate correlations can be interpreted as convergent validity coefficients. In addition, the disattenuated correlation was also estimated in order to assess the theoretical relation free from measurement errors.

For the remaining variables, independent-sample t-test were performed to compare mean stoicism scores in men vs. women. In addition, we also obtained the correlations between age and stoicism scores. All the validity analyses were conducted using SPSS v23.0 (SPSS Inc., Chicago, IL) for Windows.

\section{Results}

\section{LSS internal analyses}

The first columns in table 2 show the means and standard deviations of the LSS items. The mean for the total scale scores was 56 ( $S D=7.6$, range $30-80)$. The mean score on the original stoicism scale for the British sample (Wagstaff \& Rowledge, 1995) was $52.2(S D=13.2, n=62)$, the mean on Australian version (Murray et al., 2008) was 54,9 (SD = 9,6, $n$ = 469), the mean on the Latvian version (Gaitniece-Putāne, 2005) was 68.3 (SD =9.1, $n=195)$. The mean stoicism score in our sample was significantly higher than the British sample, $t_{(503)}=2.216, p=.030$, similar than Australian sample $t$ ${ }_{(469)}=1.924, p=.055$, and lower than the Latvia sample, $t_{(636)}$ $=-16.509, p<.001$.

We turn now to factor analysis results. Results from the 
KMO test $(.75)$ and Bartlett's test $\left(\chi^{2}{ }_{(190)}=1635.7, p<.001\right)$ suggested that the inter-item relations were consistent enough to be fitted by the FA model.

Results of optimal implementation of Parallel Analysis suggested that 4 was the most appropriate number of factors. The remaining results are in table 2. Note that BIC reaches its minimum at 4 factors, and also that the four- factor solution is the only one that leads to acceptable fit according to all criteria. Given these results we tentatively accept the 4-factor solution as the most appropriate. It should be noted that solutions in more factors were also tried but they were non-interpretable given the reduced number of variables loading in each factor.

Table 2. Results of Optimal Implementation of Parallel Analysis (PA).

\begin{tabular}{lccccc}
\hline Factor & \% explained variance & RMSEA & GFI & RMSR & NFFI \\
\hline One factor & 20.6 & .107 & .850 & .114 & .707 \\
Two factors & 32.8 & .080 & .935 & .078 & .836 \\
Three factors & 40.9 & .066 & .961 & .060 & .849 \\
Four Factors & 48.7 & .050 & .979 & .050 & .050 \\
\hline
\end{tabular}

Abbreviations: RMSEA: Root Mean Square Error of Approximation, GFI: Goodness-of-fit index, RMSR: Root Mean Square of Residuals, NNFI: Nonnormed fit index, BIC: Schwarz's Bayesian Information Criterion.

For the sake of comparison, we also note that the 4factor solution obtained here accounted for a $48.6 \%$ of the total variance, which, as expected, is higher than those obtained in previous studies: $37.9 \%$ with three factors in Latvia (Gaitniece-Putāne, 2005); 25.9\% with one factor in Australia (Murray et al., 2008), and slightly higher than British sample (47\%) that has four factors (Furnham et al., 2003).

Interpretation of an unrestricted factor solution is generally based on salience rules that are highly dependent on sample size (see e.g. Lloret-Segura et al. 2014). In our case, with a sample of 443 respondents, the approximate standard error of a loading is about 0.04 . So, the standard recommendation by McDonald (2014) that, in a reasonably large sample a minimum of 3 indicators with loadings above 0.30 are needed to define a factor seems appropriate.

The pattern of salient loadings corresponding to the 4factor solution are in the last columns of table 3, and the results can be summarized as follows: the first factor involved items about emotional concealment, items 4, 6, 8, 10, 19, 14, (e.g., 'I tend not to express my emotions'), the second refers to a favorable attitude toward expressing emotions, defined by items $7,11,12,13,15,18,20$, that (e.g., ' is healthy to express one's emotions'), the third is about problem sharing, items 5, 9, 16, 17 (e.g., 'I would not mind sharing my problems') and the fourth revolve around sentimentality, items 1 and 2 (e.g., 'I tend to cry at sad films'). The estimated marginal reliabilities of the corresponding ORION factor scores (see Ferrando \& Lorenzo-Seva, 2016) were: factor 1 (.78), factor 2 (.85), factor $3(.88)$ and factor $4(.81)$.

Even though the solution described above is relatively clear and yields reasonable reliability estimates (given the reduced number of items), some problems that will be further discussed are apparent. At the column level, the fourth fac- tor is, at best, a minor factor under-identified. And, if the pattern is assessed at the item level, we find that two items (3 and 14) do not strictly reach minimal salience. Item 14 ('One should keep a 'stiff upper lip') is a complex point that demonstrate the ability to endure hardship, more representative of factor 1 , but also with small loads in factor 2 and 3 . Item 3 ('I do not let me problems interfere with my everyday life '), has very low loading, and do not belong to any factor. As described here, stoicism refers specially to mastering one' subjective responses and so, item 3 has dubious face validity.

The inter-factor correlation matrix contained positive correlations in all cases that ranged from .16 to .45. A second-order factor analysis fitted well this matrix (RMSR= $.05, \mathrm{GFI}=.98)$, which suggests that LSS total scores could be treated as measures of a general factor of stoicism as initially intended. To further assess this issue, the loadings on the first canonical factor were also obtained. They are in the third column of table 3 . We note that the first canonical solution exhibits positive manifold, and that 11 loadings are above 0.30 . To further assess this issue we also obtained the expected common variance index (ECV; see Rodriguez, Reise, \& Haviland, 2016) using the canonical solution in one factor and the canonical solution in 4 factors. The ECV value was 0.47 which means that, of all the common variance explained by the 4-factor solution, $47 \%$ was already explained by the first general factor. Overall, we believe that these results suggest that the factors obtained in the 4-factor solution can also be viewed as facets of a more general dimension of stoicism. However, as discussed below, this issue also deserves further research. If the total scores are used, as we shall do in the validity analyses that follow, the reliability estimate for the ORION scores is .90 , while the omega reliability estimate for the raw scores is .77 . 
Table 3. Mean, Standard deviation, multidimensional item discrimination, and factor loadings of the LSS items.

\begin{tabular}{|c|c|c|c|c|c|c|c|}
\hline Questions $^{\mathrm{a}}$ & $M$ & $S D$ & c & Fact 1 & Fact 2 & Fact 3 & Fact 4 \\
\hline $4 \quad$ I tend not to express my emotions & 2.47 & 1.26 & .273 & .570 & & & \\
\hline I tend to keep my feelings to myself & 2.88 & 1.50 & .032 & .458 & .353 & & \\
\hline 10 It makes me uncomfortable when people express their emotions in front of me & 2.50 & 1.41 & .109 & .458 & .326 & & \\
\hline 19 I would not cry at the funeral of a close friend or relative & 2.65 & 1.68 & .224 & .430 & & & \\
\hline 6 I do not get emotionally involved when I see suffering on television & 2.49 & 1.43 & .239 & .412 & & & \\
\hline 14 One should keep a 'stiff upper lip' & 3.72 & 1.23 & .155 & .293 & .274 & & 272 \\
\hline 3 I do not let me problems interfere with my everyday life & 2.18 & 1.21 & 278 & 267 & & & \\
\hline 15 I believe that it is healthy to express one's emotions* & 3.77 & 1.01 & 603 & & .676 & & \\
\hline 12 I rely heavily on my friends for emotional support* & 3.67 & 1.37 & 620 & & 651 & & \\
\hline 20 Expressing one's emotions is a sign of weakness & 1.65 & 1.06 & 197 & & .548 & .335 & \\
\hline 18 A problem shared is a problem halved* & 3.15 & 1.71 & 627 & & .512 & .425 & \\
\hline 11 I don't really like people to know what I am feeling & 1.75 & .93 & 202 & & .498 & & \\
\hline 13 I always take time out to discuss problems with my family* & 3.18 & 1.27 & .534 & & .481 & & \\
\hline 7 I would consider going to a counselor if I had a problem* & 3.03 & 1.96 & .534 & & .346 & & \\
\hline 17 I would not mind sharing my problems with a female friend* & 2.69 & 1.95 & .470 & & & .802 & \\
\hline 16 Getting upset over the death of a loved one does not help & 2.38 & 1.90 & .316 & & & .595 & \\
\hline 9 I would not mind sharing my problems with a male friend* & 2.75 & 1.74 & .523 & & & .483 & \\
\hline 5 I like someone to hold me when I am upset* & 2.42 & 2.01 & .525 & & & .330 & \\
\hline 1 I tend to cry at sad films* & 2.30 & 1.69 & .486 & & & & .828 \\
\hline 2 I sometimes cry in public* & 1.63 & .77 & .448 & & & & .750 \\
\hline
\end{tabular}
Abbreviations: $M$ : mean; SD: Standard Deviation; $c$ : loadings in the first canonical factor.

\section{Validity evidence}

Patients in our sample showed higher scores on the agreeableness and conscientiousness scales of the BFI, that is, patients were kind and grateful, and were very involved in their treatment. Results of the linear regression suggested that, as of the five personality factors of BFI-10 (introversion, neuroticism, openness to experience, agreeableness, conscientiousness), only introversion had a significant weight, and was able to account for $4.1 \%$ of the variance in the stoicism scores $\left(F_{(1,401)}=18.397, p<.001\right)$. The convergent validity coefficient between the total LSS scores and the BFI introversion scores was $r_{\mathrm{xy}}=.281$, and the corresponding disattenuated estimate was .35 .

\section{Differences in clinical and social variables related to stoicism}

As expected, LSS scores were significantly higher for males $(M=57.1, S D=7.7)$ than females $(M=55.2, S D=$ $7.5, t_{(1,441)}=2.436, p=.015$, Cohen's $\left.d=.25\right)$, although effect sizes are small. Further, stoicism was positively associated with age $(r=.304, p<.001)$.

\section{Discussion}

The results of this study suggest that stoicism is an interesting and potentially useful dimension in further research in the field of oncology. The instrument analyzed, the LSS, has shortcomings and points that should be improved, but in principle exhibited acceptable psychometric properties including meaningful relations with age, gender, and with the personality dimension of introversion which went in the ex- pected direction. These findings can have implications for routine clinical practice. In our study, cancer patients who had undergone surgery exhibited moderate stoicism scores, higher than the British sample (Wagstaff \& Rowledge, 1995), similar than Australian sample (Murray et al., 2008), and lower the Latvian sample (Gaitniece-Putāne, 2005). These discrepancies could be explained in relation to three aspects: a) cultural influence, 2) age, the Australian sample were middle-aged, similar to ours, and older than participants in the other studies, and 3) the clinical setting, in our series consisted solely of patients who had just recovered from major surgery for a non-metastatic cancer facing a difficult decision about adjuvant therapy, whereas the British, Australian and Latvian samples comprised healthy individuals.

As far as the internal analysis is concerned, the Spanish version of the LSS has a structure compatible with a fourfactor solution, and the resulting subscales have acceptable reliabilities for practical use. At a higher level, this solution is also compatible with a general dimension of stoicism, and the scores derived from the general solution are highly reliable. However, at least two items showed low discriminating power in our study, and the fourth factor was essentially a doublet. Further studies are required in order to decide (a) the convenience of omitting or re-writing certain items, and (b) whether the fourth factor has theoretical relevance or merely reflects content specificity in the two implied items. Regarding point (a), items referred to emotional concealment or repression had lower discriminating power and, items 3 and 14 had very low factor loadings; in fact, the content of item 3 ('I do not let my problems interfere with my everyday life') is unique in not referring to emotions. Murray et al. (2008) suggested remove this item, and use a 19-item LSS.

As far as the scoring schema is concerned, whether it is 
more appropriate to use subscale scores or total scores in clinical assessment is an issue that requires further research. Although total scores behaved appropriately in our study, this schema necessarily implies a lost of information, and so, subscale scores, even when less reliable, might result in validity improvements. Furthermore, even if the total scores are to be used, the results obtained here suggest that fullyinformative EAP scores are far more reliable than simplesum total scores. So, even though the scoring schema is more complex, it would be recommendable to use these more accurate scores. To sum up, a revision of the scale is recommendable not only to improve its psychometric properties but also to make it easier for patients to comprehend.

The validity analyses suggested that the personality trait that best predicted stoicism was introversion. More introverted individuals prefer solitude; they tend to be uneasy in social relationships, which limits their chances to share experiences, emotions, and talk about their feelings with others; hence, the result that they have higher stoicism levels seems to be meaningful. Cancer patients overall show a higher level of introversion compared with control groups (Cardenal, Cerezo, Martínez, Ortiz-Tallo, \& Blanca, 2012). Introversion and stoic acceptance of events negatively correlates with active coping (Giese-Davis, Conrad, Nourianai, \& Spiegel, 2008; Panayiotou, Kokkinos, \& Kapsou, 2014; Rana, Gellrich, Czens, Kanatas, \& Rana, 2014).

Also as expected, stoicism was greater in older patients. It is possible that stoicism increases as part of age-related maturity, due to increased acceptance of loss as inevitable (Judd et al., 2006). Likewise, there are authors who have explained it as a cohort effect; that is, that older individuals have grown up in a culture that values abnegation and resignation (Corboy, McLaren, Jenkins, \& McDonald, 2014; Stewart \& Harmon, 2004; Wrigley, Jackson, Judd, \& Komiti, 2005), as well as stoical attitudes, for instance as regards pain, and the propensity to hide it and not seek help to avoid appearing weak (Judd et al., 2006; Yong, 2006).

There are several limitations to this study. First, despite using a larger sample than other published studies, the number of patients recruited is still rather small for subgroup analyses to be conducted based on tumor location. Thus, the

\section{References}

Addis, M. E., \& Mahalik, J. R. (2003). Men, masculinity, and the contexts of help seeking. American Psychologist, 58(1), 5-14. http://dx.doi.org/10.1037/0003-066X.58.1.5

Becker, L. C. (2003). Human health and stoic moral norms. Journal of Medicine and Philosophy, 28(2), 221-238. http://dx.doi.org/10.1076/jmep.28.2.221.14206

Benet-Martinez, V., \& John, O. P. (1998). Los Cinco Grandes across cultures and ethnic groups: multitrait multimethod analyses of the Big Five in Spanish and English. Journal of Personality and Social Psychology, 75(3), 729-750.

Buckley, J., \& Ó Tuama, S. (2010). “I send the wife to the doctor"- Men's behaviour as health consumers. International Journal of Consumer Studies, 34(5), 587-595. http://dx.doi.org/10.1111/j.1470-6431.2010.00908.x

Cardenal, V., Cerezo, M., Martínez, J., Ortiz-Tallo, M., \& Blanca, M. (2012). Personality, emotions and coping styles: Predictive value for the evolu- representation of some tumor locations is very low, among them, lung, ovaries, and skin. However, our sample does represent a true distribution of diagnoses and adjuvant treatments in outpatients with cancer. Moreover, we have substantiated that the structural validity and reliability of the scales did not differ whether or not patients with these tumor locations were included in the sample. Second, it's possible that these data might not be germane to patients with advanced tumors, whose clinical situation and prognosis differ notably.

\section{Implications for research and practice}

In summary, the results of this study indicate that stoicism is a useful concept that could be particularly interesting for future research in the field of oncology and that the LSS questionnaire is a good basis for appraising stoicism in the Spanish population with resected cancer.

Among possible clinical applications, the measurement of stoic attitudes may be related to phenomena such as acceptance and adjuvant treatment compliance, with developing self-sufficient behaviors, and might partially explain variations in tolerance in daily clinical practice. High levels of stoicism can impact help-seeking for health issues for two important reasons. First, people with such attitudes can report fewer physical symptoms for the simple reason that they fail to identify such problems as disease. If this is the case, men and older individuals may delay seeking help until their symptoms become more severe. Secondly, patients with high stoicism scores may simply be reluctant to admit that they are ill or need treatment (Fish, Prichard, Ettridge, Grunfeld, \& Wilson, 2015). More research is needed to fully explore the concept of stoicism, to examine how it interacts with other pertinent variables such as coping style, patientphysician relationship, sharing medical decision-making and help-seeking behavior.

Source of funding: This work was funded by SEOM in 2015. The sponsor of this research has not participated in the collection, analysis, or interpretation of the data, in the writing of the report, or in the decision to submit the article for publication.

tion of cancer patients. Spanish Journal of Psychology, 15, 756-767. https://dx.doi.org/10.5209/rev_SJOP.2012.v15.n2.38887

Corboy, D., McLaren, S., Jenkins, M., \& McDonald, J. (2014). The relationship between geographic remoteness and intentions to use a telephone support service among Australian men following radical prostatectomy. Psycho-Oncology, 23(11), 1259-1266. http://dx.doi.org/10.1002/pon.3559

Erskine, A. (2000). Zeno and the Beginning of Stoicism. Classics Ireland, 7, 51-60. http://dx.doi.org/10.2307/25528359

Fergus, K. D., Gray, R. E., Fitch, M. I., Labrecque, M., \& Phillips, C. (2002). Active consideration: conceptualizing patient-provided support for spouse caregivers in the context of prostate cancer. Qualitative Health Research, 12(4), http://dx.doi.org/10.1177/104973202129120034

Ferrando, P. J., \& Lorenzo-Seva U. (2014). El análisis exploratorio de ítems: 
algunas consideraciones adicionales. Anales de psicología, 30, 1170-1175. http://dx.doi.org/10.6018/analesps.30.3.1999991

Ferrando, P. J., \& Lorenzo-Seva U. (2016). A note on improving EAP trait estimation in oblique factor-analytic and item response theory models. Psicologica, 37, 235-247.

Fish, J. A., Prichard, I., Ettridge, K., Grunfeld, E. A., \& Wilson, C. (2015). Psychosocial factors that influence men's help-seeking for cancer symptoms: a systematic synthesis of mixed methods research. PsychoOncology, 24(10), 1233-1240. http://dx.doi.org/10.1002/pon.3912

Furnham, A., Petrides, K. V, Sisterson, G., \& Baluch, B. (2003). Repressive coping style and positive self-presentation. British Journal of Health Psychology, 8, 223-49. http://dx.doi.org/10.1348/135910703321649187

Gaitniece-Putāne, A. (2005). Liverpool Stoicism Scale adaptation. Baltic Journal of Psychology, 6(1), 57-64.

Gaitniece-Putāne, A. (2006). Gender and age differences in emotional intelligence, stoicism and aggression. Baltic Journal of Psychology, 7(2), 2642.

George, A., \& Fleming, P. (2004). Factors affecting men's help-seeking in the early detection of prostate cancer: implications for health promotion. Journal of Men's Health \& Gender, 1(4), 345-352. http://dx.doi.org/10.1016/j.jmhg.2004.10.009

Giese-Davis, J., Conrad, A., Nouriani, B., \& Spiegel, D. (2008). Exploring emotion-regulation and autonomic physiology in metastatic breast cancer patients: Repression, suppression, and restraint of hostility. Personality and Individual Differences, 44, 226-237. http://dx.doi.org/10.1016/j.paid.2007. 08.002

Hambleton, R. K., Merenda, P. F., \& Spielberger, C. D. (2005). Adapting educational and psychological tests for cross-cultural assessment. Mahwah, NJ: Lawrence Erlbaum.

Judd, F., Jackson, H., Komiti, A., Murray, G., Fraser, C., Grieve, A., \& Gomez, R. (2006). Help-seeking by rural residents for mental health problems: The importance of agrarian values. Australian and New Zealand Journal of Psychiatry, 40(9), 769-776. http://dx.doi.org/10.1111/j.1440-1614.2006.01882.x

Lorenzo-Seva, U. (1999). Promin: a method for oblique factor rotation. Multivariate Behavioral Research, 34(3), 347-356. http://dx.doi.org/10.1207/S15327906MBR3403 3

Lorenzo-Seva, U., \& Ferrando, P.J. (2006). FACTOR: A computer program to fit the exploratory factor analysis model. Behavioral Research Methods, Instruments and Computers, 38(1), 88-91.

Lloret-Segura, S., Ferreres-Traver, A., Hernández-Baeza, A., \& TomásMarco, I. (2014). El análisis factorial exploratorio de los ítems: Una guía práctica, revisada y actualizada. Anales de Psicologia, 30(3), 1151-1169. http://dx.doi.org/10.6018/analesps.30.3.199361

McDonald, R.P. (2014). Factor analysis and related methods. New York: Psychology Press.

Moore, A., Grime, J., Campbell, P., \& Richardson, J. (2013). Troubling stoicism: Sociocultural influences and applications to health and illness behaviour. Health (London, England: 1997), 17(2), 159-173. http://dx.doi.org/10.1177/1363459312451179

Murray, G., Allen, N. B., Rawlings, D., \& Trinder, J. (2002). Seasonally and Personality: A Prospective Investigation of Five Factor Model Correlates of Mood Seasonality. European Journal of Personality, 16(6), 457-468. http://doi.org/10.1002/per.462

Murray, G., Judd, F., Jackson, H., Fraser, C., Komiti, A., Pattison, P., ... Robins, G. (2008). Big boys don't cry: An investigation of stoicism and its mental health outcomes. Personality and Individual Differences, 44(6), 1369-1381. http://dx.doi.org/10.1016/j.paid.2007.12.005

O’Brien, R., Hunt, K., \& Hart, G. (2005). "It"s caveman stuff, but that is to a certain extent how guys still operate': men's accounts of masculinity and help seeking. Social Science \& Medicine, 61(3), 503-516. http://dx.doi.org/10.1016/j.socscimed.2004.12.008

Panayiotou, G., Kokkinos, C. M., \& Kapsou, M. (2014). Indirect and direct associations between personality and psychological distress mediated by dispositional coping. Journal of Psychology, 148, 549-567. DOI: 10.1080/00223980.2013.817375

Park, J., Kitayama, S., Karasawa, M., Curhan, K., Markus, H. R., Kawakami, N., . . Ryff, C. D. (2013). Clarifying the links between social support and health: Culture, stress, and neuroticism matter. Journal of Health Psychology, 18, 226-235. DOI: 10.1177/1359105312439731

Pinnock, C., O’Brien, B., \& Marshall, V. R. (1998). Older men's concerns about their urological health: a qualitative study. Australian and Nem Zealand Journal of Public Health, 22 (3 Suppl), 368-373.

Rammstedt, B., Goldberg, L. R., \& Borg, I. (2010). The measurement equivalence of Big-Five factor markers for persons with different levels of education. Journal of Research in Personality, 44(1), 53-61. http://dx.doi.org/10.1016/j.jrp.2009.10.005

Rammstedt, B., \& John, O. P. (2007). Measuring personality in one minute or less: A 10-item short version of the Big Five Inventory in English and German. Journal of Research in Personality, 41(1), 203-212. http://dx.doi.org/10.1016/j.jrp.2006.02.001

Rana, M., Gellrich, N. C., Czens, F., Kanatas, A., \& Rana, M. (2014). Coping with oral cancer: The impact of health and disease-related personality traits. Supportive Care in Cancer, 22, 2981-2986. http://dx.doi.org/10.1007/s00520-014-2300-6.

Rodriguez, A., Reise, S.P., \&Haviland, M.G. (2016). Evaluating bifactor models: Calculating and interpreting statistical indices. Pycohological Methods, 21(2), 137-50. http://dx.doi.org/10.1037/met0000045

Samejima, F. (1969). Estimation of a latent ability using a response pattern of graded scores. Psychometrika Monographs, 34(Suppl. 4).

Seale, C. (2002). Cancer heroics: a study of news reports with particular reference to gender. Sociology, 36(1), 107-126.

Sobralske, M. (2006). Machismo sustains health and illness beliefs of Mexican American men. Journal of the American Academy of Nurse Practitioners, 18(8), 348-350. http://dx.doi.org/10.1111/j.17457599.2006.00144.x

Spiers, J. (2006). Expressing and responding to pain and stoicism in homecare nurse-patient interactions. Scandinavian Journal of Caring Sciences, 20(3), 293-301. http://dx.doi.org/10.1111/j.1471-6712.2006.00407.x

Stewart, D., \& Harmon, K. (2004). Mental health services responding to men and their anger. International Journal of Mental Health Nursing, 13(4), 249-254. http://doi.org/10.1111/j.1440-0979.2004.00341.x

Timmerman, M. E., \& Lorenzo-Seva, U. (2011). Dimensionality Assessment of Ordered Polytomous Items with Parallel Analysis. Psychological Methods, 16, 209-220.

Wagstaff, G. F., \& Rowledge, A. M. (1995). Stoicism: Its Relation to Gender, Attitudes Toward Poverty, and Reactions to Emotive Material. The Journal of Social Psychology, 135(2), 181-184. http://dx.doi.org/10.1080/00224545.1995.9711421

Witte, T. K., Gordon, K. H., Smith, P. N., \& Van Orden, K. A. (2012). Stoicism and Sensation Seeking: Male Vulnerabilities for the Acquired Capability for Suicide. Journal of Research in Personality, 46(4), 384-392. http://dx.doi.org/10.1016/j.jrp.2012.03.004

Wrigley, S., Jackson, H., Judd, F., \& Komiti, A. (2005). Role of stigma and attitudes toward help-seeking from a general practitioner for mental health problems in a rural town. Australian and New Zealand Journal of Psychiatry, 39(6), 514-521. http://dx.doi.org/10.1111/j.14401614.2005.01612.x

Yong, H. H. (2006). Can attitudes of stoicism and cautiousness explain observed age-related variation in levels of self-rated pain, mood disturbance and functional interference in chronic pain patients? European Journal of Pain, 10(5), 399-407. http://dx.doi.org/10.1016/j.ejpain.2005.05.004

(Article received: 05-12-2016; revised: 08-02-2017; accepted: 13-03-2017) 
Appendix A. Spanish version of Liverpool Stoicism scale

*1. Suelo llorar viendo películas tristes

*2. A veces lloro en público

3. No dejo que mis problemas interfieran en mi vida privada

4. No suelo expresar mis emociones

*5. Me gusta que me abracen cuando estoy enfadado/a

6. No me siento afectado emocionalmente cuando veo sufrir en TV

*7. Iría al psicólogo si tuviera problemas

8. Suelo guardar mis sentimientos

*9. No me importa compartir mis problemas con un amigo

10. No me gusta que la gente sepa lo que siento

11. Me siento incómodo cuando la gente me expresa sus sentimientos

*12. Confío en el apoyo emocional de mis amigos

*13. Me tomo mi tiempo para discutir los problemas con mi familia

14. Se debe mantener las formas en público

*15. Es saludable expresar las propias emociones

16. Sentirse enojado por la muerte de un ser querido no ayuda

*17. No me importa compartir mis problemas con una amiga

*18. Un problema compartido es un problema reducido a la mitad

19. No suelo llorar en el funeral de un familiar o amigo

20. Expresar los sentimientos es un signo de debilidad

The format of a five-point Likert scale was: 1 (strongly-disagree), 2 (disagree), 3 (neither agree nor disagree), 4 (agree), and 5 (strongly-agree).

* Items that are scored in reverse 